Published in final edited form as:

Atherosclerosis. 2020 January ; 292: 10-16. doi:10.1016/j.atherosclerosis.2019.10.019.

\title{
Race and sex-based disparities associated with carotid endarterectomy in the Atherosclerosis Risk in Communities (ARIC) Study
}

\author{
Caitlin W. Hicks ${ }^{1}$, Natalie R. Daya², James H. Black III ${ }^{1}$, Kunihiro Matsushita², Elizabeth \\ Selvin ${ }^{2}$ \\ ${ }^{1}$ Division of Vascular Surgery and Endovascular Therapy, Johns Hopkins University School of \\ Medicine, Baltimore MD, USA \\ 2Department of Epidemiology, Johns Hopkins Bloomberg School of Public Health, Baltimore MD, \\ USA
}

\begin{abstract}
Background and aims: The indications for carotid endarterectomy (CEA) are well established. The aim of the current study was to investigate sex and race-based disparities in the incidence of CEA after adjusting for carotid artery stenosis risk factors.

Methods: We conducted a prospective cohort analysis of 14,492 black and white participants in the Atherosclerosis Risk in Communities (ARIC) study without prevalent stroke at baseline (1987-1989). We used Kaplan-Meier curves and Cox proportional hazards models adjusting for sociodemographic, cardiovascular, and disease severity risk factors to quantify the associations of sex and race with incident CEA.
\end{abstract}

Results: CEA was performed in 330 of 14,492 ARIC participants during a median of 27 years of follow-up [incidence rate 1.00 (95\% CI 0.90-1.12) per 1,000 persons-years]. The crude incidence of CEA varied significantly by sex [female vs. male: HR 0.60 (95\% CI 0.48-0.74)] and race [black vs. white: HR 0.65 (95\% CI 0.49-0.86)]. Adjustment for sociodemographic and cardiovascular risk factors, carotid intima-media thickness, and symptomatic status attenuated the association of sex with CEA [females vs. males HR $0.96(0.76-1.22)$ ], but black participants had a lower risk of incident CEA after adjustment [HR 0.68 (95\% CI 0.49-0.95)].

Conclusions: We found significant variation in the incidence of CEA procedures based on race that was independent of traditional risk factors and carotid IMT. Whether this disparity is a reflection of differences in disease presentation or access to care deserves investigation.

\section{Graphical Abstract}

\footnotetext{
Corresponding Author: Caitlin W. Hicks, 600 N Wolfe Street, Halsted 668, Baltimore, MD 21287, chicks11@jhmi.edu. Author contributions

CWH and ES conceived and designed the analysis. NRD, KM, and ES collected the data. All authors contributed to data analysis and interpretation. CWH and NRD drafted the manuscript, and all authors provided critical revisions. All authors gave final approval of the version of the manuscript submitted for publication.

Conflict of Interest Disclosures

The authors declared they do not have anything to disclose regarding conflict of interest with respect to this manuscript.
} 


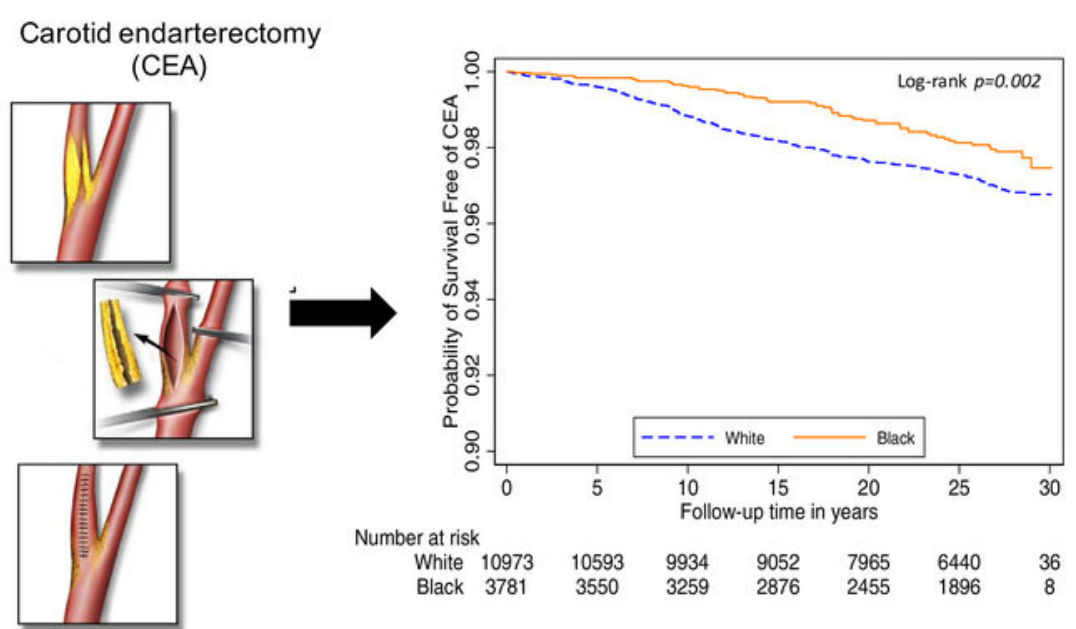

\section{Keywords}

carotid artery stenosis; carotid endarterectomy; sex; race; disparities

\section{Introduction}

The prevalence of carotid artery stenosis is estimated to be approximately $4 \%$ in the United States [1]. The risk of carotid artery stenosis has been shown to be significantly higher for persons with hypertension, smoking history, hyperlipidemia, coronary heart disease (CHD), diabetes, and chronic kidney disease (CKD) [1,2]. As a result, the American Heart Association (AHA) recommends intensive medical therapy to control hypertension, hyperlipidemia, diabetes, obesity, and encourage smoking cessation among patients with atherosclerotic disease of the extracranial carotid arteries [3].

For patients with moderate- or severe carotid artery stenosis, carotid revascularization is recommended. The Society for Vascular Surgery recommends carotid endarterectomy (CEA) for symptomatic patients with 50-99\% stenosis and asymptomatic patients with 6099\% stenosis [4]. Similarly, the AHA recommends CEA for symptomatic patients with 5099\% stenosis and asymptomatic patients with 70-99\% stenosis [3]. Based on these guidelines, nearly 50,000 CEA procedures are performed in the United States annually [5].

Despite numerous clinical trials designed to define the indications for and risks associated with CEA [6-8], there are significant sex- and race-based disparities in the management of carotid artery stenosis. Black patients have been shown to undergo less carotid artery screening than white patients $[9,10]$, and present more frequently with disabling ischemic stroke events [11]. Similarly, women undergo revascularization for carotid artery stenosis less frequently than men $[12,13]$, despite data showing equivalent periprocedural outcomes [14].

The aim of the current study was to describe risk factors associated with the incidence of CEA among a community-based population without prevalent stroke at baseline. Specifically, we investigated race and sex-based disparities in the incidence of CEA after 
adjusting for traditional carotid artery stenosis risk factors. We also investigated the association of race and sex with incident CEA among a subgroup population with symptoms suggestive of clinically significant cerebrovascular disease. Given that symptomatic carotid artery stenosis is an absolute indication for carotid revascularization [4], we did not expect to find major CEA disparities among persons with incident stroke after study enrollment or a diagnosis of symptomatic carotid disease.

\section{Patients and methods}

\section{Study cohort}

The Atherosclerosis Risk in Communities (ARIC) Study is a prospective community-based cohort study that enrolled 15,792 adults from Washington County, Maryland, Jackson, Mississippi, Forsyth County, North Carolina, and suburbs of Minneapolis, Minnesota. The study was designed to characterize the risks associated with atherosclerotic disease in the general population. ARIC participants were recruited at a baseline visit (visit 1) between 1987 and 1989, and have been followed longitudinally with serial exams and tests since that time [15]. The baseline examinations (and all subsequent examinations) were conducted by trained personnel using standardized procedures. The ARIC study is a community-based observational cohort study, and thus does not provide health care or directly influence treatment decisions of participants. In this analysis, we excluded participants who were neither white nor black $(\mathrm{N}=48)$, blacks from Minneapolis and Washington County $(\mathrm{N}=$ 55), participants missing pertinent socioeconomic data at the initial examination $(\mathrm{N}=935)$ and participants with self-reported stroke at the initial examination $(\mathrm{N}=262)$. This resulted in a study population of 14,492 participants.

All participants provided written informed consent. Institutional review boards for all participating institutions approved the study protocol.

\section{Measures}

The main exposures of interest were participant race (white vs. black) and sex (female vs. male). Other variables of interest included age, education (less than high school, high school degree or vocational school, or at least some college or professional school), family income ( $<\$ 12,000 /$ year, $\$ 12,000-\$ 24,999 /$ year, or $\$ 25,000 /$ year $)$, blood pressure, body mass index (BMI) $\left(<25 \mathrm{~kg} / \mathrm{m}^{2}, 25-<30 \mathrm{~kg} / \mathrm{m}^{2}, \geq 30 \mathrm{~kg} / \mathrm{m}^{2}\right)$, elevated low density lipoprotein (LDL)cholesterol ( $\geq 130 \mathrm{mg} / \mathrm{dL}$ ) and elevated triglyceride levels ( $\geq 150 \mathrm{mg} / \mathrm{dL}$ ) as assessed at visit 1. Cardiovascular risk factors including hypertension, coronary heart disease (CHD), chronic kidney disease (CKD), diabetes, smoking status, stroke, carotid intima-media thickness (IMT), and symptomatic status were assessed as time-varying exposures ascertained at visit 1 (1987-1989), visit 2 (1990-1992), visit 3 (1993-1994), visit 4 (1996-1998), or visit 5 (2011-2013), annual telephone contact, or active surveillance of hospital discharges in the communities. If one of the CVD risk factors assessed as time-varying exposures was missing at one of the subsequent visits, the value from the previous visit was carried forward.

Hypertension was defined based on a systolic blood pressure $\geq 140 \mathrm{mmHg}$, a diastolic blood pressure $\geq 90 \mathrm{mmHg}$, or self-reported antihypertensive medication use at any of the visits or 
by self-reported medication use or physician diagnosis during annual telephone contact after visit 4 through 2016. Coronary heart disease (myocardial infarction/fatal CHD) and stroke events were initially identified by local hospital surveillance and annual telephone contact with ARIC participants or their proxies, hospital records were obtained for all suspected cardiovascular events, and outcomes were adjudicated by an end-points committee. Details pertaining to the ascertainment and adjudication of these events have been pubished previously [16]. Serum creatinine was measured by the modified kinetic Jaffé method. Estimated glomerular filtration rate (eGFR) was calculated from serum creatinine using the Chronic Kidney Disease Epidemiology Collaboration (CKD-EPI) equation [17]. Chronic kidney disease was defined as a drop in eGFR to a level $<60 \mathrm{~mL} / \mathrm{min} / 1.73 \mathrm{~m}^{2}$ at visits 2 , 4 , or 5 accompanied by a $25 \%$ decline in eGFR from baseline, a CKD-related hospitalization or death, or incident end-stage renal disease identified through linkage with the U.S. Renal Data System [18]. Diabetes status was defined by a fasting blood glucose $\geq 126 \mathrm{mg} / \mathrm{dL}$ or a non-fasting blood glucose $\geq 200 \mathrm{mg} / \mathrm{dL}$, or self-reported physician diagnosis or diabetes medication use at any of the visits or by self-reported of medication use or physician diagnosis during annual telephone contact after visit 4 through 2016.

Carotid IMT was measured as the distance from the blood-intima to the media-adventitia interface based on the technique described and validated by Pignoli et al [19]. Carotid IMT measurements were obtained in the ARIC study via B-mode ultrasound imaging of three sites of the carotid arteries bilaterally as previously described [20,21] at visits 1,2, 3 and 4 . All four ARIC sites used a common scanning protocol [22], and the scans were read at a standardized central center [23]. For the purpose of this analysis, carotid IMT was defined as the average carotid IMT of the six measurements that were obtained.

Participants were classified as having symptomatic carotid artery stenosis via active surveillance of hospital discharges in the communities in which the participants were recruited. Any participant with a hospitalization discharge International Classification of Diseases, Ninth Revision, Clinical Modification (ICD-9-CM) code (433.11) or ICD-10-CM (10 ${ }^{\text {th }}$ Edition) code (I61.031, I61.032, I61.039, I63.131, I63.132, I63.139, I63.231, I63.232, I63.239) for carotid artery stenosis with cerebral infarction prior to CEA were classified as symptomatic. Asymptomatic carotid artery stenosis was defined by ICD-9-CM code 433.10 or ICD-10-CM codes I65.20-I65.29 prior to CEA.

\section{Outcomes}

The primary outcome of interest for the study was hospitalization for CEA after visit 1. CEA procedures were identified through two primary sources: patient self-report during annual telephone contact and active surveillance of hospital discharges in the communities in which the participants were recruited. The single level clinical classification software provided by the Agency for Healthcare Research and Quality [24]which categorizes procedure ICD-9/ ICD-10 codes to clinically meaningful categories was used for abstracting CEA. CEA was defined by clinical classification software code 51, with follow-up through 2016. 


\section{Statistical analysis}

The primary aim of our study was to describe the incidence of CEA among participants in the ARIC study without prevalent stroke at visit 1 , and to assess whether there were associations of race and sex with the incidence of CEA. As a secondary analysis, we also aimed to assess whether there were associations of race and sex with incident CEA among a cohort with symptomatic carotid artery stenosis.

Our primary analysis consisted of two stages. For the first stage, we estimated cumulative incidence of CEA overall as well as for the clinical subgroups of interest (black vs. white and female vs. male) using the Kaplan-Meier method and tested for differences using logrank tests. For the second stage of the analysis, we constructed a series of multivariable Cox proportional hazards models to describe risk factors associated with undergoing CEA. Model 1 was a crude (unadjusted) model with race and sex included as separate exposure variables. Model 2 included age, sex, race, education level, and income level. Model 3 additionally adjusted for cardiovascular risk factors, including elevated LDL-cholesterol, smoking, BMI, hypertension, diabetes, CHD, CKD, stroke, carotid IMT, and symptomatic status. As noted above, hypertension, diabetes, CHD, CKD, smoking, stroke, and symptomatic status were included as time varying exposures.

For our secondary analysis evaluating race and sex differences in the association with CEA in a cohort with high-risk cerebrovascular disease, we repeated the same analysis above but limited the cohort to only those participants with a history of stroke or a diagnosis of symptomatic carotid artery stenosis at baseline or during follow-up prior to CEA. The incidence of CEA in blacks vs. whites and females vs. males was assessed using the KaplanMeier method with log-rank tests. We then created three multivariable Cox proportional hazards models to assess the association of race and sex with incidence of CEA after adjusting for sociodemographic variables and cardiovascular risk factors. Models 1 and 2 were the same as used in the primary analysis. For model 3, the cardiovascular risk factor covariates were the same, but stroke and symptomatic status were excluded as variables because all patients were considered to have a clinically significant cerebrovascular disease.

Stata version 14.2 (StataCorp LP, TX) was used for all analyses. All p-values were two-sided and statistical significance was defined as $p<0.05$.

\section{Results}

CEA was performed in 330 of 14,492 (2.3\%) ARIC participants during a median of 27 years of follow-up (Q1-Q3 18.3-28.2 years). There were substantial differences at baseline (visit 1) between participants who underwent CEA vs. those who did not (Table 1). Participants who subsequently underwent CEA were older at baseline (56.0 \pm 5.2 vs. 54.1 \pm 5.8 years), less frequently female $(44.5 \%$ vs. $55.3 \%)$, and less frequently black (17.0\% vs. $25.5 \%)$ than nonCEA participants (all, $p<0.001$ ). Education levels were also lower in CEA participants ( $\mathrm{P}=$ 0.006 ; Table 1), although income levels $(p=0.40)$ and insurance status $(p=0.07)$ were similar between groups. Those who underwent CEA were more frequently current or former smokers $(78.1 \%$ vs. $57.8 \%)$ ( $p<0.001)$. Mean LDL-cholesterol levels $(153.8 \pm 38.9$ vs. $137.2 \pm 39.3 \mathrm{mg} / \mathrm{dL})$ and carotid IMT measurements $(0.9 \pm 0.3$ vs. $0.7 \pm 0.2 \mathrm{~mm})$ were higher 
for the CEA group (both, $p<0.001)$. The prevalence of hypertension $(57.6 \% \mathrm{vs} .42 .3 \%)$, diabetes (20.9\% vs. $11.4 \%)$, and CHD (12.5\% vs. 4.4\%) were also higher for the CEA group (all, $p<0.001$ ). There were no statistically significant differences in BMI or eGFR-cr $<60$ $\mathrm{mL} / \mathrm{min} / 1.73 \mathrm{~m}^{2}$ between groups (both, $p>0.11$ ).

\section{Crude incidence rates of CEA}

The crude incidence rate (IR) of CEA overall was 1.00 (95\% CI 0.90-1.12) per 1,000 persons-years. When stratified by race, the IR for CEA (per 1,000 person years) was higher in whites [IR 1.09 (95\% CI 0.98-1.24)] vs. blacks [IR 0.71 (95\% 0.55-0.92)] (log-rank $p=0.003$; Figure 1, Panel A). When stratified by sex, the IR for CEA (per 1,000 person years) was higher in males [IR 1.30 (95\% CI 1.13-1.51)] vs. females [IR 0.78 (95\% 0.670.92)] (log-rank $p<0.001$; Figure 1B).

\section{Cox proportional hazards analyses of CEA risk}

There were significant associations of both sex and race with CEA in the unadjusted analysis (Model 1, Table 2). Females had a lower risk of CEA than males [HR 0.60 (95\% CI 0.480.74)], and blacks had a lower risk of CEA than whites [HR 0.65 (95\% CI 0.49-0.86)]. After adjusting for age, education, and income level (Model 2), both the sex [female vs. male HR 0.60 (95\% CI 0.48-0.75)] and race [black vs. white HR 0.55 (95\% CI 0.40-0.76)] differences in CEA risk persisted. Additional adjustment for cardiovascular risk factors, symptomatic status, and carotid IMT (Model 3) substantially attenuated the association of sex with CEA [females vs. males HR 0.96 (95\% 0.76-1.22)], but the association of race with CEA remained significant [blacks vs. whites 0.68 (95\% CI 0.49-0.95)]. There were no substantial changes in these findings if patients with prevalent self-reported transient ischemia attacks at baseline were additionally excluded from analysis. There were also no substantial changes to the findings if carotid IMT was removed as a covariate in the multivariable model (Supplementary Table 1).

Other factors that were independently associated with risk of CEA included increasing age, income level $<\$ 12,000$, elevated LDL levels, current or former smoking, prevalent CHD, prior stroke, symptomatic status, and increasing carotid IMT (all, P < 0.05; Model 3, Table 2).

\section{Secondary analysis}

Among 1,915 participants with stroke or symptomatic CAS at baseline or during follow-up, CEA was performed in 95 instances [IR 2.40 (95\% CI 1.95-2.93) per 1,000 person-years]. The crude risk of CEA was lower in females vs. males [HR 0.67 (95\% CI 0.45-1.01)] and lower in blacks Vs. whites [HR 0.59 (95\% CI 0.36-0.97)]. Similar to the primary analysis, the association of sex and race with CEA was significant after adjusting for age and socioeconomic factors (Table 3), but the association of sex with CEA was attenuated after adjusting for cardiovascular risk factors, symptomatic status, and carotid IMT [females vS. males HR 0.89 (95\% CI 0.56-1.40)]. The association of race with CEA persistent after adjustment for major risk factors [blacks $v s$. whites HR 0.50 (95\% CI 0.28-0.91)], although the confidence interval for this estimate is wide due to the small numbers of events. 


\section{Discussion}

Despite guidelines from the SVS and the AHA recommending CEA for moderate and highgrade carotid artery stenosis [3, 4], we found significant differences in the crude incidence rates of CEA procedures performed in ARIC participants based on sex and race. Female participants underwent fewer CEA procedures than male participants, and black participants underwent fewer CEA procedures than white participants. The sex-based disparity was attenuated after adjusting for socioeconomic and cardiovascular risk factors, but the racial disparity persisted even in fully adjusted models. These findings suggest that the previously reported sex-based differences in CEA may be reflective of differences in risk factor profiles, whereas the race-based CEA differences may be independent of traditional risk factors or severity of carotid stenosis.

There are a number of previous reports documenting racial disparities for cardiovascular interventions in the literature [25-28]. Based on an analysis of data from the Veterans Affairs (VA) hospitals, Whittle et al. showed that whites were more likely to undergo invasive cardiac procedures than blacks, including cardiac catheterization, angioplasty, and coronary artery bypass surgery [28]. This difference persisted after adjusting for sociodemographic, comorbidity, and hospital-based factors. Schulman et al. further explored this observation using a blinded computerized survey instrument to assess biases in physicians' recommendations for cardiac catheterization based on scripted actor interviews [29]. They found that both race and sex independently influenced how physicians managed chest pain, with women and blacks being less frequently referred for catheterization than men and whites, respectively. Although the etiology of these differences is unclear, some experts theorize that they may be reflective of perceived clinical outcome differences in one group over another [28-30]. Consistent with this notion, blacks have been shown to have worse outcomes after CEA than whites [31, 32], which may partially explain our finding of a lower adjusted risk of CEA in blacks.

The challenge with reporting population differences in procedure rates is a lack of detailed information about disease presentation and symptomatic status in datasets that were not desiged to specifically evaluate carotid artery interventions. These details are important when considering differences in procedure rates because they impact the indication and urgency for surgical intervention. Both the SVS and AHA guidelines have different thresholds for CEA depending on whether a patient is symptomatic [3, 4]. Persons with symptomatic carotid artery stenosis are recommended to undergo CEA for any stenosis between $50 \%$ and $99 \%$ stenosis. In contrast, CEA is only recommended for asymptomatic persons with higher ( $>60-70 \%)$ grade stenosis. The impact of this distinction is suggested in our analysis. Of all the factors considered in our adjusted model (Model 3), high-risk cerebrovascular disease features including carotid IMT, a diagnosis of symptomatic carotid artery stenosis, and stroke were the three strongest risk factors for CEA.

Although we can account for symptomatic status using hospitalization diagnosis codes for symptomatic carotid artery stenosis and stroke, carotid pathology may differ based on sex and race [33-36]. In the ARIC study, carotid wall thickness has been shown to vary by both race and sex [37, 38], possibly as a result of differences in lipoprotein(a) levels [37]. The 
association between carotid IMT and stroke has also been shown to be stronger in blacks compared to whites in the ARIC population [39]. We performed a secondary analysis limited to participants with stroke or symptomatic carotid artery stenosis in an attempt to reduce heterogeneity in the severity of carotid disease we were studying. Even in this analysis, blacks had a persistently lower hazard ratio for CEA than whites.

Interestingly, the difference in CEA incidence for blacks versus whites that we observed was significant even after adjusting for traditional cardiovascular risk factors, stroke, symptomatic status, and carotid IMT. The etiology of the race-based disparities for CEA that we describe is unclear, but may be reflective of socioeconomic factors, differences in access to care, and/or differences in cultural attitudes toward surgery. We accounted for socioeconomic status by adjusting for education and income in our adjusted models, but differences in access to care and cultural attitudes toward healthcare are more difficult to capture. There is some evidence that socioeconomic status may affect carotid IMT differently for blacks versus whites. Ranjit et al. have shown that socioeconomic status is positively associated with IMT progression among middle-aged blacks, whereas it is inversely related to IMT progression among middle-aged whites [40]. Pothof et al. recently reported that black patients undergoing CEA tend to present with a higher vascular disease burden and are less likely to be operated on in a high-volume hospital or by a high-volume surgeon [41]. These findings support those of Epstein et al., who showed that minority patients in New York City are substantially less likely to use both high-volume hospitals and surgeons for cancer, cardiovascular, and orthopedic procedures [42]. Black race has also been shown to be a risk factor for longer times between diagnosis and CEA among patients with carotid stenosis warranting surgery [43], suggesting that there are more delays in scheduling black patients for an intervention than white patients even after a diagnosis is obtained.

While some of these issues may be due to health care access and utilization disparities, there are also patient factors that may play a role. Margolis et al. showed that black patients with lung cancer were more frequently opposed to surgical resection than white patients due to a widespread belief within the black community that there is accelerated tumor spread with surgery [44]. Similarly, Hausmann et al. showed that total joint replacements are offered less frequently to blacks, but that the difference is not significant after accounting for patient preference for surgery [45]. No similar qualitative studies investigated the racial disparities associated with carotid interventions, but it is possible that blacks are more hesitant to undergo surgery than whites due to fear or distrust of physicians and/or invasive procedures [46], which could partially explain the race-based differences in CEA incidence rates that we observed. Regardless of the reason for these differences, it is important that patient education - including a discussion about the risks associated with carotid artery stenosis and the available treatment options - be had with all patients who present with the disease. These conversations should be initiated by both primary care physicians and specialty physicians (i.e. vascular surgeon, cardiologist, etc.), with the goal of allowing for informed, shared patient decision making about undergoing carotid revascularization if and when it is appropriate. 
Although we observed a significant association of sex with CEA in our crude analysis, the association was attenuated after adjusting for cardiovascular risk factors and symptomatic status. There was a persistent difference in CEA rates among females versus males after adjusting for race and socioeconomic factors, but this difference was no longer significant after adjusting for comorbid disease, symptomatic status, and carotid IMT. These findings are notable because they suggest that the previously reported sex-based disparities in CEA procedures $[12,13]$ is more a reflection of indication rather than a true disparity [30]. Based on previous data from the ARIC study, females are known to have different carotid artery atherosclerotic profiles and risk factors than men [38, 47, 48]. Females are also less likely to have a major stroke than males $[49,50]$, and some studies suggest that periprocedural complications after carotid revascularization may be higher [51-53]. Our data from this community-based study suggest that CEA are performed slightly less frequently in females compared to males, but not significantly so once cardiovascular and symptomatic risk factors are considered.

A main limitation of this study is the lack information regarding indication for surgery in affected participants. We included stroke as a covariate in the analysis to represent symptomatic status, and we used hospitalization diagnosis codes to extract additional information regarding the presence of symptomatic carotid artery stenosis. However, data on amarousis fugax and other symptoms possibly attributable to carotid artery disease are limited. In addition, the indication for CEA in asymptomatic participants cannot be determined. We also cannot account for degree of carotid artery stenosis or the distribution of disease in our analysis, which may differ between races and by sex. We included carotid IMT in our fully adjusted model in an attempt to partially adjust for this. Carotid IMT has been shown to correlate with future risk of stroke [48], but other high-risk characteristics such as carotid bifurcation geometry, plaque calcification, echogenicity, and progression over time were not considered [54-56]. These characteristics could be obtained from computed tomography or standard carotid duplex studies, which are unfortunately not available in this cohort. In addition, we did not account for risk factors such as diet in our adjusted analysis. Recently, a Southern dietary pattern and dietary ratio of sodium to potassium were shown to be key factors mediating racial differences in indicent hypertension among black versus white adults [57]. It is possible that lifestyle factors other than smoking and cholesterol levels could be confounding the risk of CEA in blacks versus whites. Finally, there is a potential for race-site aliasing inherent to the ARIC Study design. Blacks were recruited primarily at just two field centers in the ARIC study, so we are not able to separate out any effects of race from geography. Racial disparities in cardiac revascularization may be partially explained by county variation [58], so it is possible that geographic variation in carotid revascularization could similarly explain some of the racebased disparity in incidence of CEA that we observed.

\section{Conclusions}

While there are known sex and race-based differences in the prevalence of carotid artery stenosis, we found significant variation in the incidence of CEA based on race that is independent of traditional risk factors and carotid IMT. Whether this disparity is a reflection of differences in disease presentation or access to care deserves investigation. 


\section{Supplementary Material}

Refer to Web version on PubMed Central for supplementary material.

\section{Acknowledgements}

The authors thank the staff and participants of the ARIC study for their important contributions.

Financial support

The Atherosclerosis Risk in Communities study has been funded in whole or in part with Federal funds from the National Heart, Lung, and Blood Institute, National Institutes of Health, Department of Health and Human Services, under Contract No. (HHSN268201700001I, HHSN268201700002I, HHSN268201700003I, HHSN268201700005I, HHSN268201700004I). Dr. Selvin was supported by NIH/NIDDK grants K24DK106414 and R01DK089174. Dr. Matsushita was supported by NHLBI grant R21HL133694.

\section{References}

[1]. Wilcox T, Newman JD, Maldonado TS, Rockman C, Berger JS, Peripheral vascular disease risk in diabetic individuals without coronary heart disease, Atherosclerosis 275 (2018) pp. 419-425. [PubMed: 29801688]

[2]. Kajitani N, Uchida HA, Suminoe I, Kakio Y, Kitagawa M, Sato H, et al., Chronic kidney disease is associated with carotid atherosclerosis and symptomatic ischaemic stroke, J Int Med Res 46 (2018) pp. 3873-3883. [PubMed: 29968487]

[3]. Brott TG, Halperin JL, Abbara S, Bacharach JM, Barr JD, Bush RL, et al., 2011 ASA/ ACCF/AHA/AANN/AANS/ACR/ASNR/CNS/SAIP/SCAI/SIR/SNIS/SVM/SVS guideline on the management of patients with extracranial carotid and vertebral artery disease: executive summary. A report of the American College of Cardiology Foundation/American Heart Association Task Force on Practice Guidelines, and the American Stroke Association, American Association of Neuroscience Nurses, American Association of Neurological Surgeons, American College of Radiology, American Society of Neuroradiology, Congress of Neurological Surgeons, Society of Atherosclerosis Imaging and Prevention, Society for Cardiovascular Angiography and Interventions, Society of Interventional Radiology, Society of NeuroInterventional Surgery, Society for Vascular Medicine, and Society for Vascular Surgery, Circulation 124 (2011) pp. 489-532. [PubMed: 21282505]

[4]. Ricotta JJ, Aburahma A, Ascher E, Eskandari M, Faries P, Lal BK, et al., Updated Society for Vascular Surgery guidelines for management of extracranial carotid disease, J Vasc Surg 54 (2011) pp. e1-31. [PubMed: 21889701]

[5]. Lichtman JH, Jones MR, Leifheit EC, Sheffet AJ, Howard G, Lal BK, et al., Carotid Endarterectomy and Carotid Artery Stenting in the US Medicare Population, 1999-2014, JAMA 318 (2017) pp. 1035-46. [PubMed: 28975306]

[6]. Moresoli P, Habib B, Reynier P, Secrest MH, Eisenberg MJ, Filion KB, Carotid Stenting Versus Endarterectomy for Asymptomatic Carotid Artery Stenosis: A Systematic Review and MetaAnalysis, Stroke 48 (2017) pp. 2150-7. [PubMed: 28679848]

[7]. Raman G, Moorthy D, Hadar N, Dahabreh IJ, O'Donnell TF, Thaler DE, et al., Management strategies for asymptomatic carotid stenosis: a systematic review and meta-analysis, Ann Intern Med 158 (2013) pp. 676-85. [PubMed: 23648949]

[8]. Lokuge K, de Waard DD, Halliday A, Gray A, Bulbulia R, Mihaylova B, Meta-analysis of the procedural risks of carotid endarterectomy and carotid artery stenting over time, Br J Surg 105 (2018) pp. 26-36. [PubMed: 29205297]

[9]. Martin KD, Naert L, Goldstein LB, Kasl S, Molinaro AM, Lichtman JH, Comparing the use of diagnostic imaging and receipt of carotid endarterectomy in elderly black and white stroke patients, J Stroke Cerebrovasc Dis 21 (2012) pp. 600-6. [PubMed: 21411337]

[10]. Oddone EZ, Horner RD, Sloane R, McIntyre L, Ward A, Whittle J, et al., Race, presenting signs and symptoms, use of carotid artery imaging, and appropriateness of carotid endarterectomy, Stroke 30 (1999) pp. 1350-6. [PubMed: 10390306] 
[11]. Oddone EZ, Horner RD, Johnston DC, Stechuchak K, McIntyre L, Ward A, et al., Carotid endarterectomy and race: do clinical indications and patient preferences account for differences? Stroke 33 (2002) pp. 2936-43. [PubMed: 12468794]

[12]. Kuy S, Seabrook GR, Rossi PJ, Lewis BD, Dua A, Brown KR, Management of carotid stenosis in women, JAMA Surg 148 (2013) pp. 788-90. [PubMed: 23804123]

[13]. De Rango P, Brown MM, Leys D, Howard VJ, Moore WS, Paciaroni M, et al., Management of carotid stenosis in women: consensus document, Neurology 80 (2013) pp. 2258-68. [PubMed: 23751919]

[14]. Jim J, Dillavou ED, Upchurch GR Jr, Osborne NH, Kenwood CT, Siami FS, et al., Genderspecific 30-day outcomes after carotid endarterectomy and carotid artery stenting in the Society for Vascular Surgery Vascular Registry, J Vasc Surg 59 (2014) pp. 742-8. [PubMed: 24246542]

[15]. The Atherosclerosis Risk in Communities (ARIC) Study: design and objectives. The ARIC investigators, Am J Epidemiol 129 (1989) pp. 687-702. [PubMed: 2646917]

[16]. White AD, Folsom AR, Chambless LE, Sharret AR, Yang K, Conwill D, et al., Community surveillance of coronary heart disease in the Atherosclerosis Risk in Communities (ARIC) Study: methods and initial two years' experience, J Clin Epidemiol 49 (1996) pp. 223-33. [PubMed: 8606324]

[17]. Levey AS, Stevens LA, Schmid CH, Zhang YL, Castro AF 3rd, Feldman HI, et al., A new equation to estimate glomerular filtration rate, Ann Intern Med 150 (2009) pp. 604-12. [PubMed: 19414839]

[18]. Grams ME, Chow EK, Segev DL, Coresh J, Lifetime incidence of CKD stages 3-5 in the United States, Am J Kidney Dis 62 (2013) pp. 245-52. [PubMed: 23566637]

[19]. Pignoli P, Tremoli E, Poli A, Oreste P, Paoletti R, Intimal plus medial thickness of the arterial wall: a direct measurement with ultrasound imaging, Circulation 74 (1986) pp. 1399-406. [PubMed: 3536154]

[20]. Chambless LE, Heiss G, Folsom AR, Rosamond W, Szklo M, Sharrett AR, et al., Association of coronary heart disease incidence with carotid arterial wall thickness and major risk factors: the Atherosclerosis Risk in Communities (ARIC) Study, 1987-1993, Am J Epidemiol 146 (1997) pp. 483-94. [PubMed: 9290509]

[21]. Pang Y, Sang Y, Ballew SH, Grams ME, Heiss G, Coresh J, et al., Carotid Intima-Media Thickness and Incident ESRD: The Atherosclerosis Risk in Communities (ARIC) Study, Clin J Am Soc Nephrol 11 (2016) pp. 1197-205. [PubMed: 27073198]

[22]. National Heart, Lung, and Blood Institute, Atherosclerosis Risk in Communities (ARIC) Study. Operations Manual, No. 6A: Ultrasound Scanning Methods, Version1.0, (1987).

[23]. National Heart, Lung, and Blood Institute, Atherosclerosis Risk in Communities (ARIC) Study Operations Manual, No. 6B: Ultrasound Reading Methods, Version 1.0, (1987).

[24]. Agency for Healthcare and Research Quality (AHRQ), Clinical classifications software (CCS) 2015, (2015).

[25]. Peterson ED, Wright SM, Daley J, Thibault GE, Racial variation in cardiac procedure use and survival following acute myocardial infarction in the Department of Veterans Affairs, JAMA 271 (1994) pp. 1175-80. [PubMed: 8151875]

[26]. Peterson ED, Shaw LK, DeLong ER, Pryor DB, Califf RM, Mark DB, Racial variation in the use of coronary-revascularization procedures. Are the differences real? Do they matter? N Engl J Med 336 (1997) pp. 480-6. [PubMed: 9017942]

[27]. Conigliaro J, Whittle J, Good CB, Hanusa BH, Passman LJ, Lofgren RP, et al., Understanding racial variation in the use of coronary revascularization procedures: the role of clinical factors, Arch Intern Med 160 (2000) pp. 1329-35. [PubMed: 10809037]

[28]. Whittle J, Conigliaro J, Good CB, Lofgren RP, Racial differences in the use of invasive cardiovascular procedures in the Department of Veterans Affairs medical system, N Engl J Med 329 (1993) pp. 621-7. [PubMed: 8341338]

[29]. Schulman KA, Berlin JA, Harless W, Kerner JF, Sistrunk S, Gersh BJ, et al., The effect of race and sex on physicians' recommendations for cardiac catheterization, N Engl J Med 340 (1999) pp. 618-26. [PubMed: 10029647] 
[30]. Mark DB, Shaw LK, DeLong ER, Califf RM, Pryor DB, Absence of sex bias in the referral of patients for cardiac catheterization, N Engl J Med 330 (1994) pp. 1101-6. [PubMed: 8133852]

[31]. Brown HA, Sullivan MC, Gusberg RG, Dardik A, Sosa JA, Indes JE, Race as a predictor of morbidity, mortality, and neurologic events after carotid endarterectomy, J Vasc Surg 57 (2013) pp. 1325-30. [PubMed: 23375438]

[32]. Dardik A, Bowman HM, Gordon TA, Hsieh G, Perler BA, Impact of race on the outcome of carotid endarterectomy: a population-based analysis of 9,842 recent elective procedures, Ann Surg 232 (2000) pp. 704-9. [PubMed: 11066143]

[33]. Markert MS, Della-Morte D, Cabral D, Roberts EL Jr, Gardener H, Dong C, et al., Ethnic differences in carotid artery diameter and stiffness: the Northern Manhattan Study, Atherosclerosis 219 (2011) pp. 827-32. [PubMed: 21906739]

[34]. D’Agostino RB Jr, Burke G, O’Leary D, Rewers M, Selby J, Savage PJ, et al., Ethnic differences in carotid wall thickness. The Insulin Resistance Atherosclerosis Study, Stroke 27 (1996) pp. 1744-9. [PubMed: 8841322]

[35]. Sacco RL, Roberts JK, Boden-Albala B, Gu Q, Lin IF, Kargman DE, et al., Race-ethnicity and determinants of carotid atherosclerosis in a multiethnic population. The Northern Manhattan Stroke Study, Stroke 28 (1997) pp. 929-35. [PubMed: 9158627]

[36]. Vaidya D, Heckbert SR, Wasserman BA, Ouyang P, Sex-specific association of age with carotid artery distensibility: multi-ethnic study of atherosclerosis, J Womens Health (Larchmt) 21 (2012) pp. 516-20. [PubMed: 22393881]

[37]. Schreiner PJ, Heiss G, Tyroler HA, Morrisett JD, Davis CE, Smith R, Race and gender differences in the association of $\mathrm{Lp}$ (a) with carotid artery wall thickness. The Atherosclerosis Risk in Communities (ARIC) Study, Arterioscler Thromb Vasc Biol 16 (1996) pp. 471-8. [PubMed: 8630675]

[38]. Howard G, Sharrett AR, Heiss G, Evans GW, Chambless LE, Riley WA, et al., Carotid artery intimal-medial thickness distribution in general populations as evaluated by B-mode ultrasound. ARIC Investigators, Stroke 24 (1993) pp. 1297-304. [PubMed: 8362421]

[39]. Ohira T, Shahar E, Iso H, Chambless LE, Rosamond WD, Sharrett AR, et al., Carotid artery wall thickness and risk of stroke subtypes: the atherosclerosis risk in communities study, Stroke 42 (2011) pp. 397-403. [PubMed: 21164133]

[40]. Ranjit N, Diez-Roux AV, Chambless L, Jacobs DR Jr, Nieto FJ, Szklo M, Socioeconomic differences in progression of carotid intima-media thickness in the Atherosclerosis Risk in Communities study, Arterioscler Thromb Vasc Biol 26 (2006) pp. 411-6. [PubMed: 16322533]

[41]. Pothof AB, Soden PA, Deery SE, O'Donnell TFX, Wang GJ, Hughes K, et al., The impact of race on outcomes after carotid endarterectomy in the United States, J Vasc Surg 68 (2018) pp. 426-35. [PubMed: 29482877]

[42]. Epstein AJ, Gray BH, Schlesinger M, Racial and ethnic differences in the use of high-volume hospitals and surgeons, Arch Surg 145 (2010) pp. 179-86. [PubMed: 20157087]

[43]. Wise ES, Ladner TR, Song J, Eagle SS, Mocco J, Wergin JE, et al., Race as a predictor of delay from diagnosis to endarterectomy in clinically significant carotid stenosis, J Vasc Surg 62 (2015) pp. 49-56. [PubMed: 25776188]

[44]. Margolis ML, Christie JD, Silvestri GA, Kaiser L, Santiago S, Hansen-Flaschen J, Racial differences pertaining to a belief about lung cancer surgery: results of a multicenter survey, Ann Intern Med 139 (2003) pp. 558-63. [PubMed: 14530226]

[45]. Hausmann LR, Mor M, Hanusa BH, Zickmund S, Cohen PZ, Grant R, et al., The effect of patient race on total joint replacement recommendations and utilization in the orthopedic setting, $\mathrm{J}$ Gen Intern Med 25 (2010) pp. 982-8. [PubMed: 20509053]

[46]. Boulware LE, Cooper LA, Ratner LE, LaVeist TA, Powe NR, Race and trust in the health care system, Public Health Rep 118 (2003) pp. 358-65. [PubMed: 12815085]

[47]. Loboz-Rudnicka M, Jaroch J, Bociaga Z, Rzyczkowska B, Uchmanowicz I, Polanski J, et al., Impact of cardiovascular risk factors on carotid intima-media thickness: sex differences, Clin Interv Aging 11 (2016) pp. 721-31. [PubMed: 27307718] 
[48]. Chambless LE, Folsom AR, Clegg LX, Sharrett AR, Shahar E, Nieto FJ, et al., Carotid wall thickness is predictive of incident clinical stroke: the Atherosclerosis Risk in Communities (ARIC) study, Am J Epidemiol 151 (2000) pp. 478-87. [PubMed: 10707916]

[49]. Rosamond W, Flegal K, Friday G, Furie K, Go A, Greenlund K, et al., Heart disease and stroke statistics--2007 update: a report from the American Heart Association Statistics Committee and Stroke Statistics Subcommittee, Circulation 115 (2007) pp. e69-171. [PubMed: 17194875]

[50]. Turtzo LC, McCullough LD, Sex differences in stroke, Cerebrovasc Dis 26 (2008) pp. 462-74. [PubMed: 18810232]

[51]. Giannopoulos S, Katsanos AH, Vasdekis SN, Boviatsis E, Voumvourakis KI, Tsivgoulis G, Age and gender disparities in the risk of carotid revascularization procedures, Neurol Sci 34 (2013) pp. 1711-7. [PubMed: 23666437]

[52]. Howard VJ, Lutsep HL, Mackey A, Demaerschalk BM, Sam AD 2nd, Gonzales NR, et al., Influence of sex on outcomes of stenting versus endarterectomy: a subgroup analysis of the Carotid Revascularization Endarterectomy versus Stenting Trial (CREST), Lancet Neurol 10 (2011) pp. 530-7. [PubMed: 21550314]

[53]. Rothwell PM, Eliasziw M, Gutnikov SA, Warlow CP, Barnett HJ, Carotid Endarterectomy Trialists Collaboration, Endarterectomy for symptomatic carotid stenosis in relation to clinical subgroups and timing of surgery, Lancet 363 (2004) pp. 915-24. [PubMed: 15043958]

[54]. Bijari PB, Wasserman BA, Steinman DA, Carotid bifurcation geometry is an independent predictor of early wall thickening at the carotid bulb, Stroke 45 (2014) pp. 473-8. [PubMed: 24357655]

[55]. Gupta A, Baradaran H, Schweitzer AD, Kamel H, Pandya A, Delgado D, et al., Carotid plaque MRI and stroke risk: a systematic review and meta-analysis, Stroke 44 (2013) pp. 3071-7. [PubMed: 23988640]

[56]. Brinjikji W, Rabinstein AA, Lanzino G, Murad MH, Williamson EE, DeMarco JK, et al., Ultrasound Characteristics of Symptomatic Carotid Plaques: A Systematic Review and MetaAnalysis, Cerebrovasc Dis 40 (2015) pp. 165-74. [PubMed: 26279159]

[57]. Howard G, Cushman M, Moy CS, Oparil S, Muntner P, Lackland DT, et al., Association of Clinical and Social Factors With Excess Hypertension Risk in Black Compared With White US Adults, JAMA 320 (2018) pp. 1338-48. [PubMed: 30285178]

[58]. Li S, Chen A, Mead K, Racial disparities in the use of cardiac revascularization: does local hospital capacity matter? PLoS One 8 (2013) pp. e69855. [PubMed: 23875005] 


\section{Highlights}

- The crude incidence of carotid endarterectomy varied significantly by sex and race

- $\quad$ Adjustment for sociodemographic and cardiovascular risk factors, carotid intima-media thickness, and symptomatic status attenuated the association of sex with carotid endarterectomy

- $\quad$ Black participants had a persistently lower risk of incident carotid endarterectomy after risk adjustment 


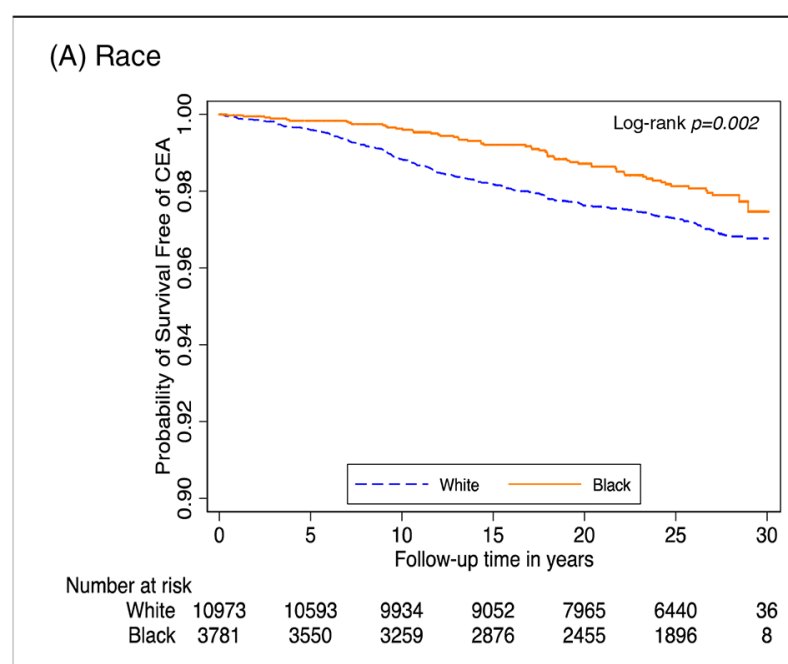

(B) Sex

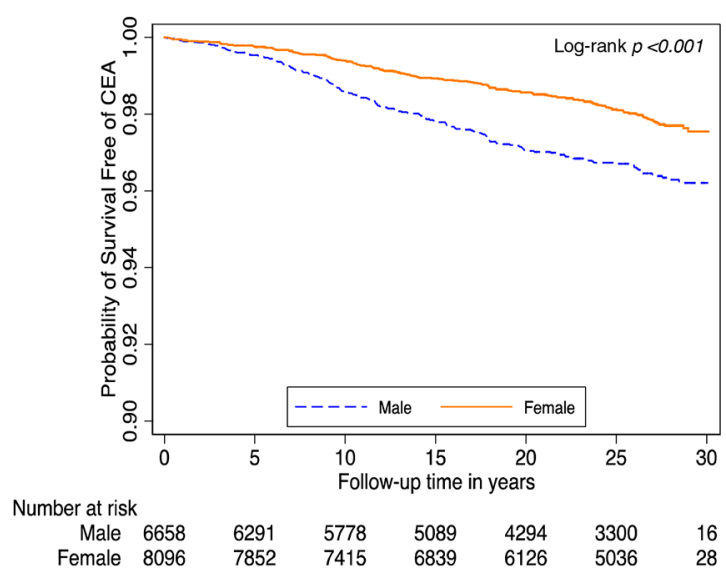

Figure 1.

Kaplan Meier curves showing the incidence of carotid endarterectomy by race and sex among ARIC participants 1987-2016.

(A) When stratified by race, the crude incidence of CEA was higher in whites $v s$. blacks (log-rank $p=0.003$ ). (B) When stratified by sex, the crude incidence of CEA was higher in males vs. females (log-rank $p<0.001)$. 
Table 1.

Baseline characteristics of ARIC participants (1987-1989) stratified by incident hospitalization for carotid endarterectomy (CEA), 1987-2016.

\begin{tabular}{|c|c|c|c|}
\hline Characteristic & No Incident CEA & Incident CEA & $p$-value \\
\hline $\mathrm{N}, \%$ & $14162(97.7 \%)$ & $330(2.3 \%)$ & \\
\hline Age, years & $54.1 \pm 5.8$ & $56.0 \pm 5.2$ & $<.001$ \\
\hline Female sex & $55.3 \%$ & $44.5 \%$ & $<.001$ \\
\hline Black race & $25.5 \%$ & $17.0 \%$ & $<.001$ \\
\hline Education level & & & .006 \\
\hline Less than high school & $23.1 \%$ & $30.6 \%$ & \\
\hline High school or vocational school & $41.2 \%$ & $37.3 \%$ & \\
\hline College or higher & $35.8 \%$ & $32.1 \%$ & \\
\hline Income level & & & .40 \\
\hline$<\$ 12,000$ & $15.4 \%$ & $16.7 \%$ & \\
\hline$\$ 12,000-\$ 24,999$ & $22.2 \%$ & $24.6 \%$ & \\
\hline $2 \$ 25,000$ & $62.4 \%$ & $58.8 \%$ & \\
\hline Insurance status & & & 0.07 \\
\hline Private & $87.8 \%$ & $87.3 \%$ & \\
\hline Medicare & $28.8 \%$ & $38.6 \%$ & \\
\hline Medicaid & $5.1 \%$ & $4.7 \%$ & \\
\hline Other & $9.4 \%$ & $11.3 \%$ & $<.001$ \\
\hline Smoking status & & & $<.001$ \\
\hline Current & $25.6 \%$ & $37.5 \%$ & \\
\hline Former & $32.2 \%$ & $40.6 \%$ & \\
\hline Never & $42.2 \%$ & $22.0 \%$ & \\
\hline LDL level, mg/dL & $137.2 \pm 39.3$ & $153.8 \pm 38.9$ & $<.001$ \\
\hline Elevated LDL ( $\geq 130 \mathrm{mg} / \mathrm{dL})$ & $53.6 \%$ & $70.7 \%$ & $<.001$ \\
\hline \multicolumn{4}{|l|}{ Body mass index } \\
\hline$<25 \mathrm{~kg} / \mathrm{m}^{2}$ & $33.2 \%$ & $30.4 \%$ & .114 \\
\hline $25-<30 \mathrm{~kg} / \mathrm{m}^{2}$ & $39.4 \%$ & $44.9 \%$ & \\
\hline $230 \mathrm{~kg} / \mathrm{m}^{2}$ & $27.4 \%$ & $24.6 \%$ & \\
\hline Hypertension $^{a}$ & $42.3 \%$ & $57.6 \%$ & $<.001$ \\
\hline Diabetes $b$ & $11.4 \%$ & $20.9 \%$ & $<.001$ \\
\hline Coronary heart disease ${ }^{c}$ & $4.4 \%$ & $12.5 \%$ & $<.001$ \\
\hline eGFR-cr $<60 \mathrm{~mL} / \mathrm{min} / 1.73 \mathrm{~m}^{2}$ & $1.2 \%$ & $1.8 \%$ & .34 \\
\hline Carotid intima-media thickness, $\mathrm{mm}$ & $0.7 \pm 0.2$ & $0.9 \pm 0.3$ & $<.001$ \\
\hline
\end{tabular}

\footnotetext{
${ }^{a}$ Hypertension was defined as systolic blood pressure $\geq 140 \mathrm{mmHg}$, a diastolic blood pressure $\geqslant 00 \mathrm{mmHg}$, or self-reported antihypertensive medication use

$b_{\text {Diak }}$ self-reported diabetes medication use
}

Atherosclerosis. Author manuscript; available in PMC 2021 January 01. 
${ }^{c}$ Coronary heart disease was defined by self-reported prior physician diagnosis of myocardial infarction or coronary revascularization, or prevalent myocardial infarction by 12-lead ECG at visit 1 . 
Table 2.

Hazard ratios $(95 \% \mathrm{CI})$ for the association of race and sex with carotid endarterectomy (CEA) among ARIC participants 1987-2016.

\begin{tabular}{|c|c|c|c|}
\hline & $\begin{array}{c}\text { Model 1 }^{a} \\
\text { HR (95\% CI) }\end{array}$ & $\begin{array}{c}\text { Model } 2 \\
\text { HR (95\% CI) }\end{array}$ & $\begin{array}{c}\text { Model } 3 \\
\text { HR (95\% CI) }\end{array}$ \\
\hline Age, per year & - & $1.07(1.05,1.09)$ & $1.03(1.01,1.05)$ \\
\hline Female vs. male & $0.60(0.48,0.74)$ & $0.60(0.48,0.75)$ & $0.96(0.76,1.22)$ \\
\hline Black vs. white & $0.65(0.49,0.87)$ & $0.55(0.40,0.76)$ & $0.68(0.49,0.95)$ \\
\hline \multicolumn{4}{|l|}{ Education level } \\
\hline Less than high school & - & $1.50(1.10,2.03)$ & $0.97(0.71,1.34)$ \\
\hline High school or vocational school & - & $1.01(0.78,1.32)$ & $0.91(0.70,1.19)$ \\
\hline College or higher & - & 1 (Reference) & 1 (Reference) \\
\hline \multicolumn{4}{|l|}{ Income level } \\
\hline$<\$ 12,000$ & - & $1.57(1.09,2.27)$ & $1.47(1.02,2.13)$ \\
\hline$\$ 12,000-\$ 24,999$ & - & $1.23(0.93,1.63)$ & $1.12(0.84,1.49)$ \\
\hline $2 \$ 25,000$ & - & 1 (Reference) & 1 (Reference) \\
\hline \multicolumn{4}{|l|}{ Body mass index, per $\mathrm{kg} / \mathrm{m}^{2}$} \\
\hline$<25 \mathrm{~kg} / \mathrm{m}^{2}$ & - & - & 1 (Reference) \\
\hline $25-<30 \mathrm{~kg} / \mathrm{m}^{2}$ & - & - & $1.06(0.82,1.38)$ \\
\hline $230 \mathrm{~kg} / \mathrm{m}^{2}$ & - & - & $0.84(0.61,1.15)$ \\
\hline Elevated LDL-C ( $\geq 130 \mathrm{mg} / \mathrm{dL})$ & - & - & $1.68(1.32,2.13)$ \\
\hline \multicolumn{4}{|l|}{ Smoking status $b$} \\
\hline Current & - & - & $2.53(1.83,3.50)$ \\
\hline Former & - & - & $1.85(1.38,2.47)$ \\
\hline Never & - & - & 1 (Reference) \\
\hline Hypertension $b$ & - & - & $1.10(0.85,1.43)$ \\
\hline Diabetes $b$ & - & - & $0.93(0.68,1.27)$ \\
\hline Stroke ${ }^{b}$ & - & - & $2.61(1.82,3.76)$ \\
\hline Symptomatic status $b$ & - & - & $4.05(2.73,5.99)$ \\
\hline Coronary heart disease ${ }^{b}$ & - & - & $1.94(1.41,2.67)$ \\
\hline Chronic kidney disease ${ }^{b}$ & - & - & $1.22(0.85,1.73)$ \\
\hline Carotid intima-media thickness, per mm & - & - & $5.38(4.31,6.73)$ \\
\hline
\end{tabular}

${ }^{a}$ Based on crude (unadjusted) Cox proportional hazards model; race and sex were analyzed as separate exposure variables

$b_{\text {Time varying exposures }}$ 
Table 3.

Secondary analysis of the association of race and sex with carotid endarterectomy (CEA) among ARIC participants with stroke or a diagnosis of symptomatic carotid artery stenosis at baseline or during follow-up, $\mathrm{N}=1,915$.

\begin{tabular}{|c|c|c|c|}
\hline & $\begin{array}{c}\text { Model 1 }^{a} \\
\text { HR (95\% CI) }\end{array}$ & $\begin{array}{c}\text { Model } 2 \\
\text { HR (95\% CI) }\end{array}$ & $\begin{array}{c}\text { Model } 3 \\
\text { HR (95\% CI) }\end{array}$ \\
\hline Age, per year & - & $1.03(0.99,1.07)$ & $1.02(0.97,1.06)$ \\
\hline Female vs. male & $0.67(0.45,1.01)$ & $0.60(0.39,0.93)$ & $0.89(0.56,1.40)$ \\
\hline Black vs. white & $0.59(0.36,0.97)$ & $0.40(0.22,0.71)$ & $0.50(0.28,0.91)$ \\
\hline \multicolumn{4}{|l|}{ Education level } \\
\hline Less than high school & - & $0.90(0.52,1.56)$ & $0.76(0.43,1.32)$ \\
\hline High school or vocational school & - & $0.71(0.43,1.19)$ & $0.68(0.41,1.14)$ \\
\hline College or higher & - & 1 (Reference) & 1 (Reference) \\
\hline \multicolumn{4}{|l|}{ Income level } \\
\hline$<\$ 12,000$ & - & $3.04(1.64,5.61)$ & $2.71(1.47,5.01)$ \\
\hline$\$ 12,000-\$ 24,999$ & - & $1.47(1.87,2.50)$ & $1.48(0.88,2.51)$ \\
\hline $2 \$ 25,000$ & - & 1 (Reference) & 1 (Reference) \\
\hline \multicolumn{4}{|l|}{ Body mass index, $\mathrm{kg} / \mathrm{m}^{2}$} \\
\hline$<25 \mathrm{~kg} / \mathrm{m}^{2}$ & - & - & 1 (Reference) \\
\hline $25-<30 \mathrm{~kg} / \mathrm{m}^{2}$ & - & - & $1.33(0.79,2.23)$ \\
\hline $230 \mathrm{~kg} / \mathrm{m}^{2}$ & - & - & $1.24(0.69,2.23)$ \\
\hline Elevelated LDL-C $(\geq 130 \mathrm{mg} / \mathrm{dL})$ & - & - & $1.90(1.18,3.08)$ \\
\hline \multicolumn{4}{|l|}{ Smoking status $b$} \\
\hline Current & - & - & $2.88(1.56,5.34)$ \\
\hline Former & - & - & $2.03(1.16,3.57)$ \\
\hline Never & - & - & 1 (Reference) \\
\hline Hypertension $b$ & - & - & $1.03(0.62,1.69)$ \\
\hline Diabetes $b$ & - & - & $1.11(0.66,1.88)$ \\
\hline Coronary heart disease $b$ & - & - & $1.67(0.96,2.91)$ \\
\hline Chronic kidney disease ${ }^{b}$ & - & - & $0.82(0.44,1.52)$ \\
\hline Carotid intima-media thickness, per mm & - & - & $3.70(2.39,5.73)$ \\
\hline
\end{tabular}

${ }^{a}$ Based on crude (unadjusted) Cox proportional hazards model; race and sex were analyzed as separate exposure variables

$b_{\text {Time varying exposures }}$ 